\title{
Simulation and dSPACE Hardware Implementation of Carrier based SVPWM for Open-end Induction motor
}

\author{
A Sriharibabu ${ }^{1}$, G Srinivasa Rao ${ }^{2}$ \\ 1,2 Department of Electrical \& Electronics Engineering, Vignan's Foundation for Science, Technology and Research \\ Vadlamudi-522213, INDIA. \\ ${ }^{1}$ sriharielectrical@gmail.com, ${ }^{2}$ srn.gorantla@gmail.com
}

\begin{abstract}
\end{abstract}
This paper deals with the implementation of carrier based Space vector pulse width modulated methods (SVPWM) in conjunction with a three phase open end induction motor(OEIM). Among various PWM methods, now a day's carrier based PWM methods draws more attention due to their easier digital implementation. The main focus of this paper is effortless digital implementation of PWM methods to drive the open end induction motor which is supplied using two dc to ac converters (VSI), using various carrier-based Space vector PWM schemes. MATLAB Simulink platform is used to simulate different carrier based PWM methods for the VSI fed Induction motor. In the present work $\mathrm{SSPACE} 1104$ is used for the digital implementation. The simulation and hardware results which are obtained from various modulation techniques for the proposed model are secure produced by using voltage and current waveforms, FFT analysis, and the most predominantly the THD is slighter. Theoretical and realistic values are corroborating by simulation and experimentation. (VSI).

Keywords: Carrier Based SVPWM, Fast Fourier transforms (FFT) Analysis, IM drive, SVPWM, Voltage Source Inverter

$$
\text { open end induction motor. }
$$

\section{Introduction}

More trending in power electronics have led to attentiveness in voltage source inverters with pulse width modulation technique of AC drives. A number of PWM techniques are used to capture changeable voltage (V) and frequency (Hz) supply [1-3]. The pulse width modulation techniques for dc to ac converter i.e. VSI are sine PWM and space vector PWM which are expansive. There is a great rise in usage of space vector PWM because of their straight forward and effortless digital realization and superior for providing efficacious DC bus utilization. Moreover, in comparison to the sinusoidal PWM, the foster Carrier based SVPWM technique has beneath switching losses, and superior harmonic performance. This technique provides superior $\mathrm{dc}$ bus utilization and it reduces time [4-5]. So, this paper gives a clear-cut idea about the execution of this proceeding technique implemented on an induction motor drive. This paper deals with the implementation of carrier based Space vector pulse width modulated methods (SVPWM) in conjunction with a three phase
2. Pulse width modulation

The distinct PWM techniques are as under:

A. Sinusoidal PWM

B. Space Vector PWM

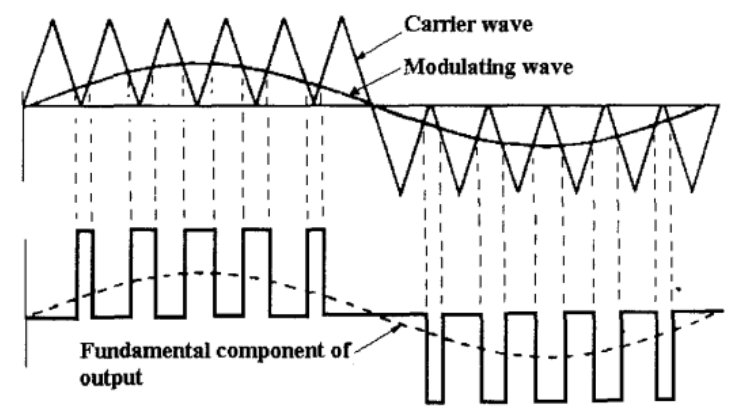

Fig.1. Pulses generation by sine wave as a reference

\section{A. Sinusoidal PWM:}

To gives rise to the gate pulses, the sine-wave is to analyze with triangular wave. This technique is well known prominent for industrial converters [4]. 


\section{B. Space Vector PWM:}

The inverter with eight switching states as shown in exhibited in Fig.2. From those eight switching states, six active states and rest of the two are zero states. The active voltage vector is fabricated by the active states each which results in dividing the SV plane into six sectors and are of uniform magnitude each. The voltage reference vector is come up with the rotating vector, which is examined once in every sub-cycle, Ts in space vector PWM. It provides the advantage of better utilization of dc link utilization as compared with the sinusoidal PWM. But this conventional SVPWM suffers with complex computations and sector selection. And it also suffers with the disadvantage of poorer performance at high modulation index. In order to avoid these grievances without sacrificing its better dc link utilization, carrier based PWM methods came into picture [5].

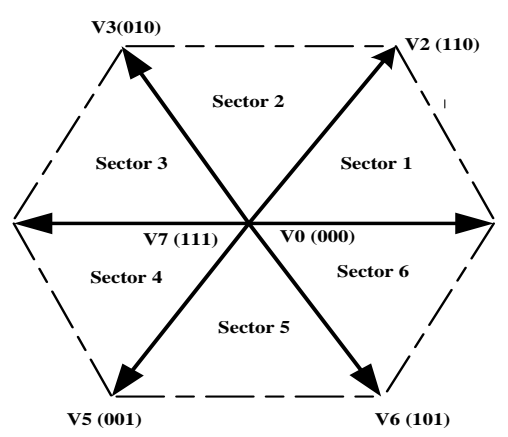

Fig.2. Pulses generation by sine wave as a reference

\section{Carrier based svpwm}

This innovative technique comes up with quick and systematic process for accomplishment of SVPWM without sector requirement. It is based completely hinged with duty ratio characteristics that the carrier based SVPWM gives rise to higher frequency triangular carrier pulses which are stipulated by equating the duty ratio as the sinusoidal pulse width modulation technique.

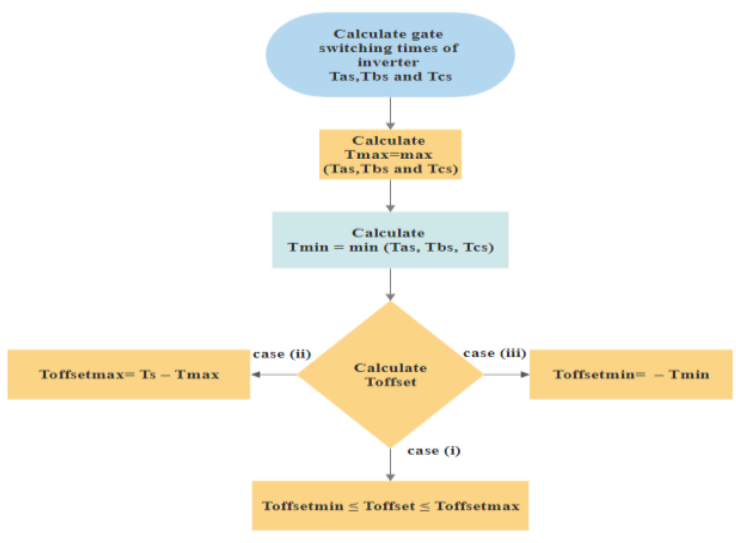

Copyright $\subset$ C Authors
It involves the sequential approach to provide gating signals to the three legs of converter having a,b and $\mathrm{c}$ as phases[5].

\section{Fig.3. Flow chart for obtaining offset times}

Fig. 3 represents the flow chart where the steps need to be followed in order to provide the offset times which are necessary for getting gating times (Tga, Tgb and Tgc). Equations 1 and 2 can be used to calculate the gating times from the offset times and results three different modulating signals as shown in fig. 4 for dc link voltage of Vdc.

$$
\begin{aligned}
& \text { Tgx }=\text { Txs }+ \text { Toffset } \\
& \text { Txs }=(\text { Ts/Vdc }) * V x s * \quad(x=a, b, c)
\end{aligned}
$$

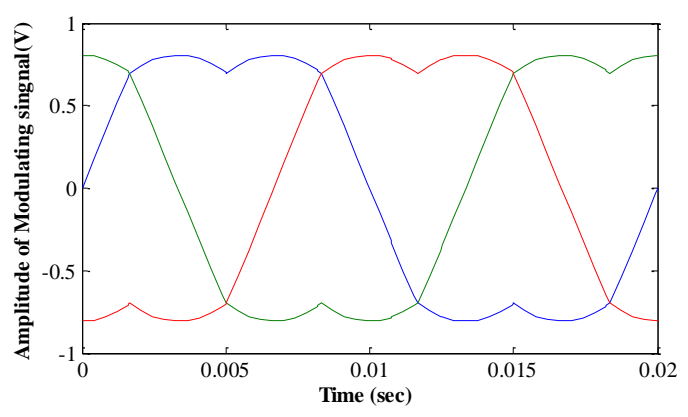

Fig.4. Modulating wave generated for carrier based PWM

The selection of Toffset from the three different cases mentioned in the above flow chart yields three different carrier based PWM gating signals as shown in fig. 3

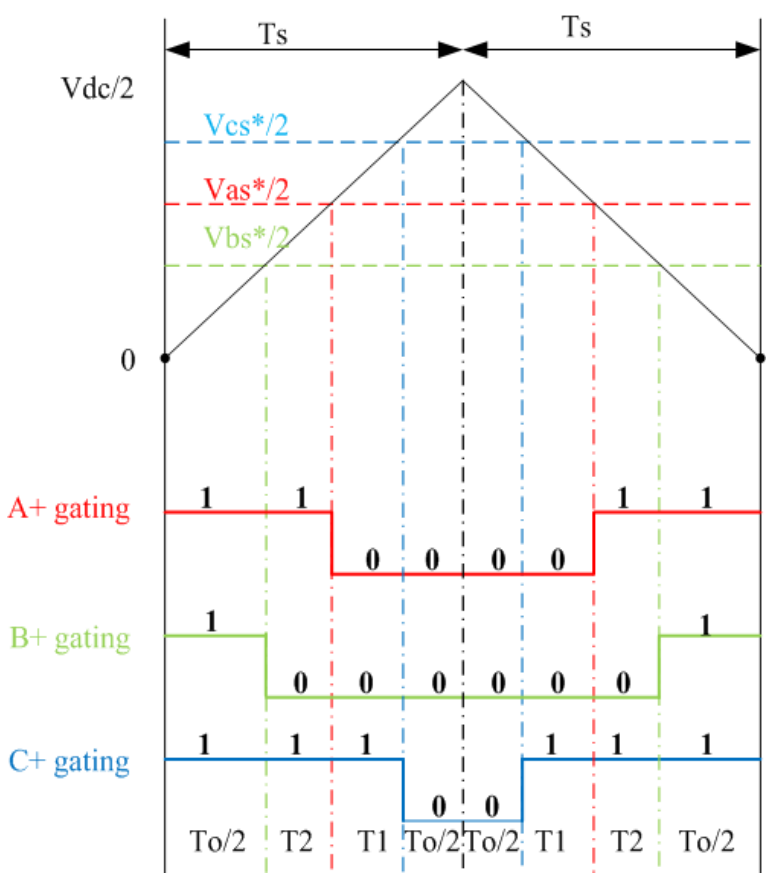


(a)

(b)

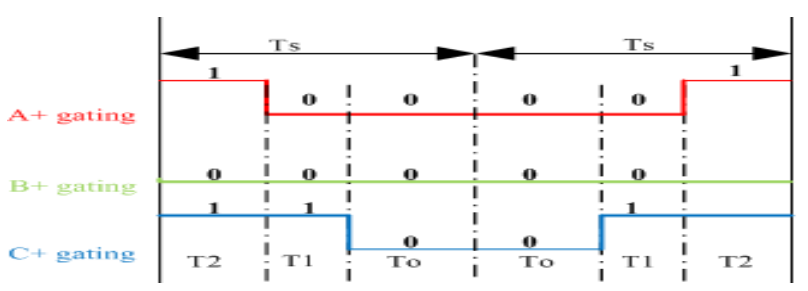

(c)

Fig. 5. (a) gating pulses with case (i), (b)gating signals with case (ii), (c)gating signals with case (iii)

Fig.5 illustrates that with case (i), Toffset calculation results the center sampling time spaced PWM implementation whereas case (ii) or case (iii), Toffset calculations give rise the center sampling time spaced PWM implementations.

\section{Validation of induction motor model}

The Simulink model of three phase induction motor which is available at MATLAB Simulink Library is employed in order to evaluate the performance of the above mentioned carrier based PWM methods.

TABLE 1. MOTOR SPECIFICATIONS

\begin{tabular}{|l|l|}
\hline Parameters & Ratings \\
\hline Rated power & $1 \mathrm{HP}$ \\
\hline Rated voltage & $415 \mathrm{~V}$ \\
\hline Rated speed & $1415 \mathrm{RPM}$ \\
\hline Pole pairs & 2 \\
\hline Stator resistance & $16.92 \Omega$ \\
\hline Rotor resistance & $7.771 \Omega$ \\
\hline $\begin{array}{l}\text { Stator leakage } \\
\text { inductance }\end{array}$ & $0.0418 \mathrm{H}$ \\
\hline $\begin{array}{l}\text { Rotor leakage } \\
\text { inductance }\end{array}$ & $0.0418 \mathrm{H}$ \\
\hline $\begin{array}{l}\text { Rotor time } \\
\text { constant }(\mathrm{J})\end{array}$ & $0.0082 \mathrm{Kg} . \mathrm{m}^{\wedge} 2$ \\
\hline Friction factor(F) & $0.000001 \mathrm{Nm} . \mathrm{s}$ \\
\hline
\end{tabular}

The specifications listed in the Table 1 are used in order to simulate the motor and the simulation results are validated through experimentation. Table 2 shows that there is very good agreement between simulation and experimental results.

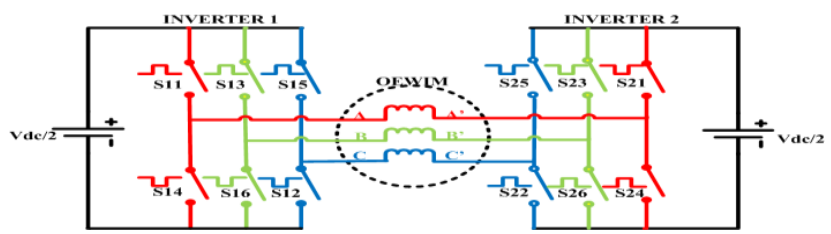

Copyright $($ C Authors
Fig.6. Dual inverter fed open end induction motor

5. Simulation result analysis

The above mentioned carrier based PWM methods are implemented in MATLAB Simulink platform. And the gating signals are feed to the three phase open end induction motor in conjunction with 2 two level inverters as shown in fig. 6 .

TABLE 2.

\begin{tabular}{|c|c|c|c|}
\hline \multicolumn{4}{|c|}{ Simulation Results } \\
\hline $\begin{array}{c}\text { Voltage } \\
\text { (V) }\end{array}$ & $\begin{array}{l}\text { Speed } \\
(\mathrm{rpm})\end{array}$ & $\begin{array}{c}\text { Torque } \\
(\mathrm{Nm})\end{array}$ & $\begin{array}{l}\text { Current } \\
\text { (A) }\end{array}$ \\
\hline 415 & 1487 & 1.066 & 1.112 \\
\hline 415 & 1472 & 2.133 & 1.192 \\
\hline 415 & 1462 & 2.844 & 1.281 \\
\hline 415 & 1451 & 3.556 & 1.395 \\
\hline 415 & 1441 & 4.125 & 1.502 \\
\hline 415 & 1434 & 4.55 & 1.592 \\
\hline 415 & 1423 & 5.12 & 1.724 \\
\hline \multicolumn{4}{|c|}{ Experimental Results } \\
\hline $\begin{array}{c}\text { Voltage } \\
\text { (V) }\end{array}$ & $\begin{array}{c}\text { Speed } \\
(\mathrm{rpm})\end{array}$ & $\begin{array}{l}\text { Torque } \\
(\mathrm{Nm})\end{array}$ & $\begin{array}{l}\text { Current } \\
\text { (A) }\end{array}$ \\
\hline 415 & 1486 & 1.066 & 1.208 \\
\hline 415 & 1474 & 2.133 & 1.303 \\
\hline 415 & 1464 & 2.844 & 1.396 \\
\hline 415 & 1454 & 3.556 & 1.48 \\
\hline 415 & 1448 & 4.125 & 1.57 \\
\hline 415 & 1438 & 4.55 & 1.67 \\
\hline 415 & 4128 & 5.12 & 1.8 \\
\hline
\end{tabular}

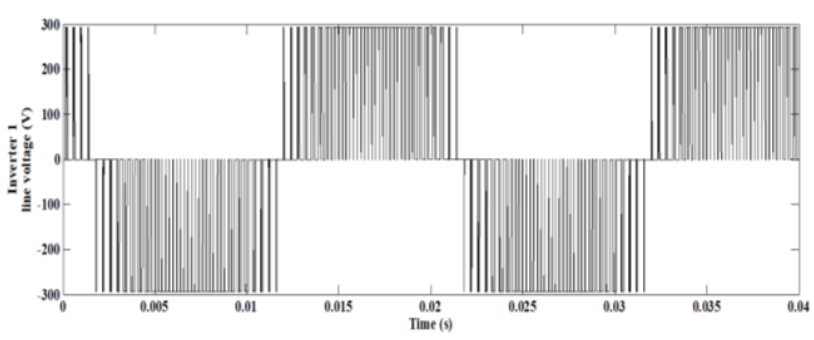

(a)

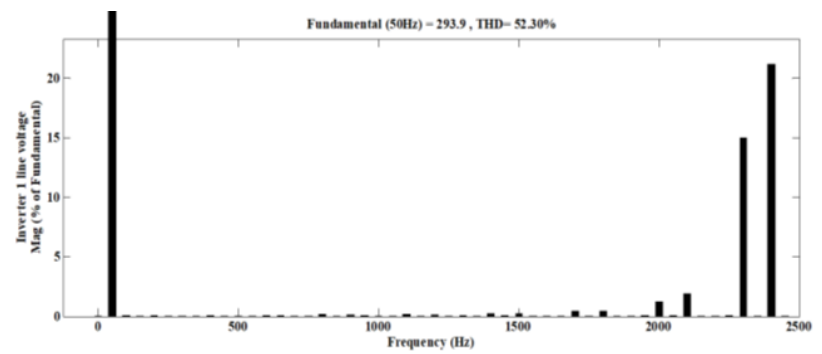

(b)

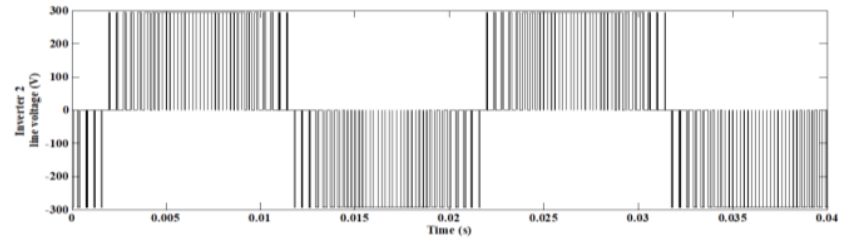

240

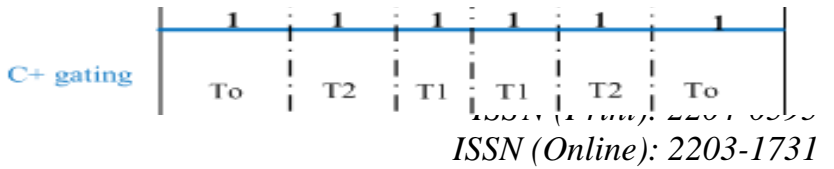


(c)

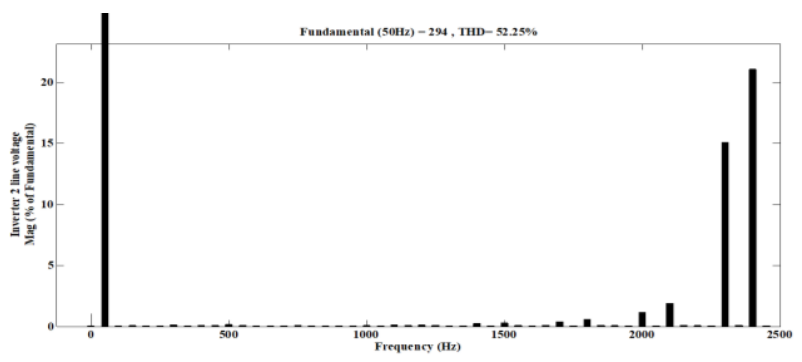

(d)

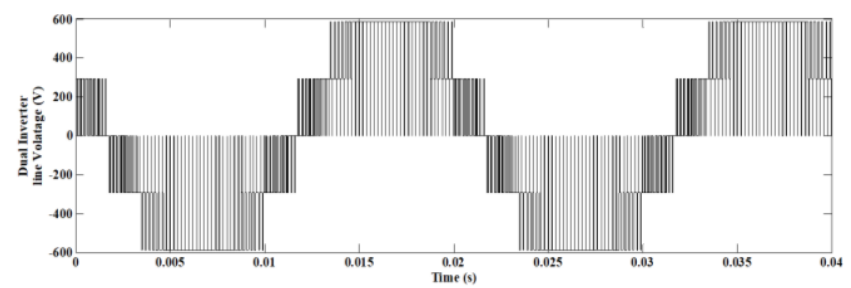

(e)

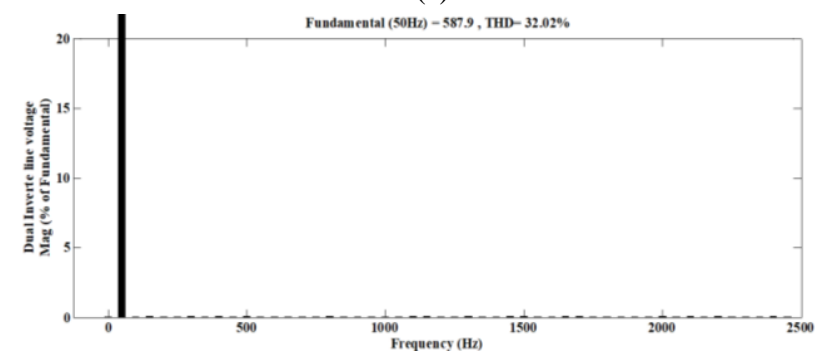

(f)

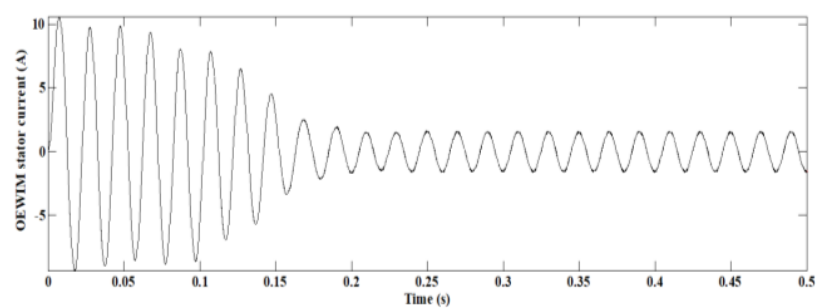

(g)

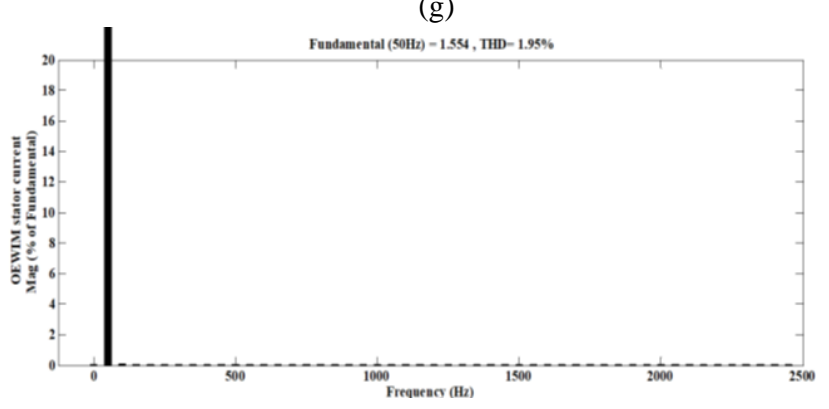

(h)

Fig.7.Dual inverter fed open end motor output waveforms

The simulation is carried out at different modulation index values in the linear range of carried based SVPWM

Copyright $($ C Authors at constant $\mathrm{V} / \mathrm{f}$ control of induction motor with the switching frequency of $2.5 \mathrm{kHz}$. Fig.7 shows the dual inverter fed open end motor no load voltage and current wave forms at maximum linear range modulation index value of 0.866 along with their harmonic spectra. The dc link voltage $\mathrm{Vdc}$ is taken as $600 \mathrm{~V}$ to feed the rated power to motor. It is observed from the above results that the dual inverter line voltage i.e. phase voltage of induction motor is at less THD value of $32.02 \%$ while compared with either of inverter 1 and inverter 2 THD value of $52.25 \%$.

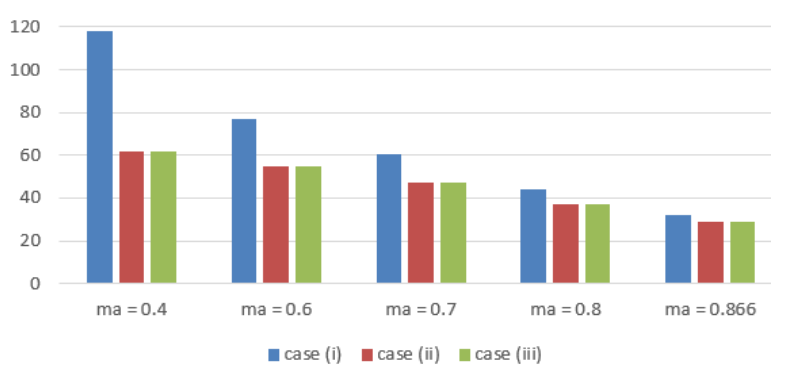

(a)

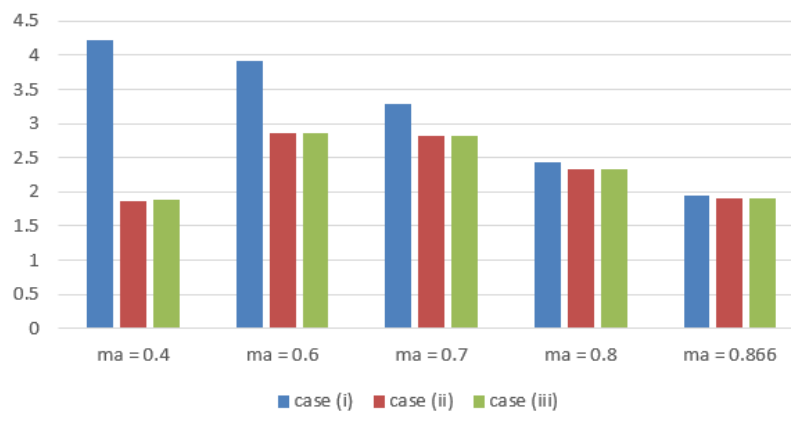

(b)

Fig.8. (a) Variation in \% THD of dual inverter voltage

(b) Variation in \% THD of motor stator current

The comparative study of the three possible carrier based PWM implementations as mentioned earlier as three different cases also presented in Fig.8. In this figure the superiority of case (ii) and case (iii) PWM strategies shown over case (i) strategy by considering THD distortions of dual inverter voltage and motor stator currents at different modulation index (ma) values.

\section{Hardware implementation}

The digital implementation of carrier based SVPWM is practically carried out by downloading the above MATLAB simulated PWM gating signals into dSPACE 1104 kit. Fig.9 illustrates the experimental setup of dual inverter fed open end induction motor. The experimental setup shown in fig.9 is equipped with 2 two level inverters feeding $1 \mathrm{hp}$ open end induction with the specifications 
listed in Table 1. The two inverters are fed with equal dc link voltages of $300 \mathrm{~V}$ each at modulation index of 0.866 .

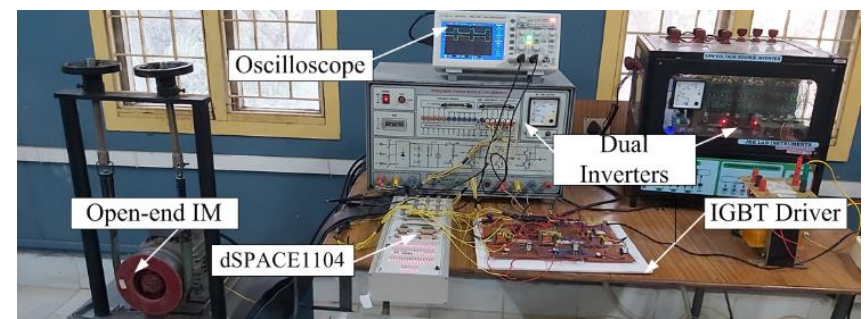

Fig.9. Experimental setup

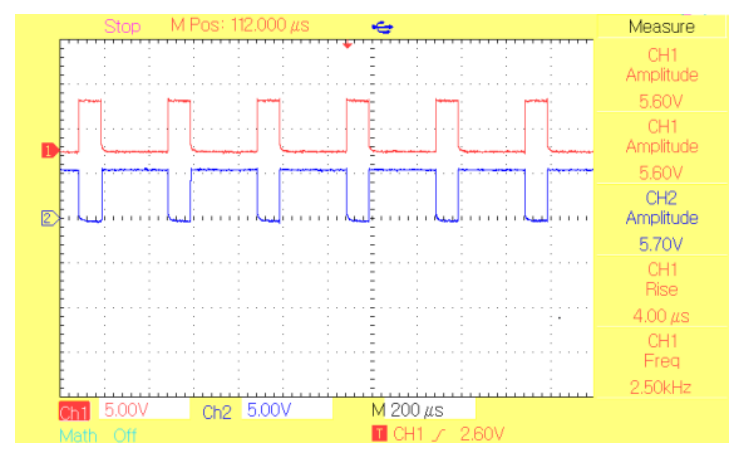

Fig.10. dSPACE generated Pulses

Fig.10 shows the PWM pulses generated from dSPACE kit at switching frequency of $2.5 \mathrm{kHz}$. Fig. 11 shows the hardware results of dual inverter fed open end induction motor at no load. The hardware results of voltage and current wave forms along with FFT windows are successfully presented for dual inverter fed open end induction motor with effortless implementation of carrier based PWM method using dSPACE.

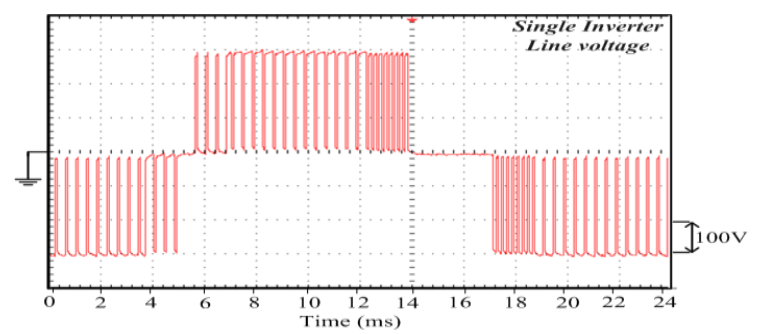

(a)

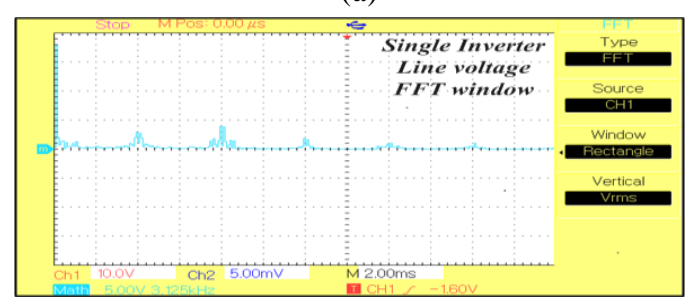

Copyright $\subset$ C Authors (b)

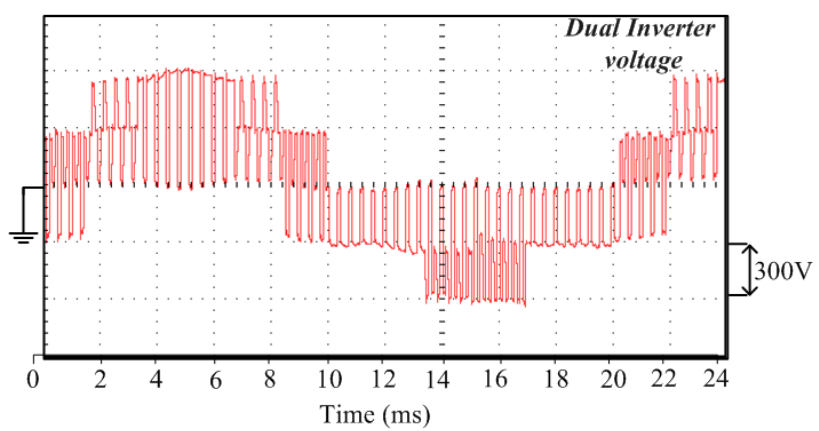

(c)

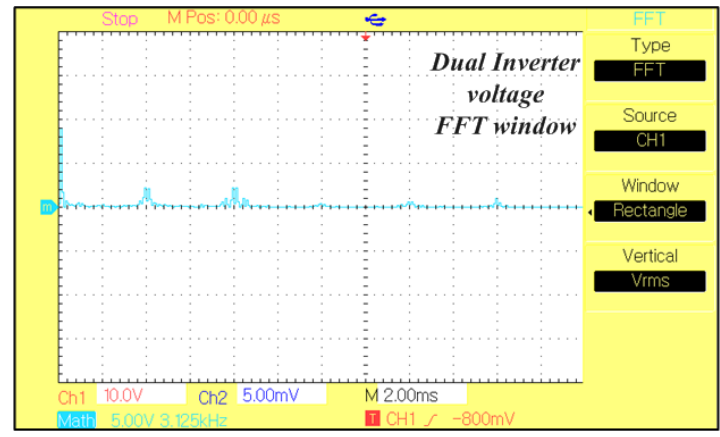

(d)

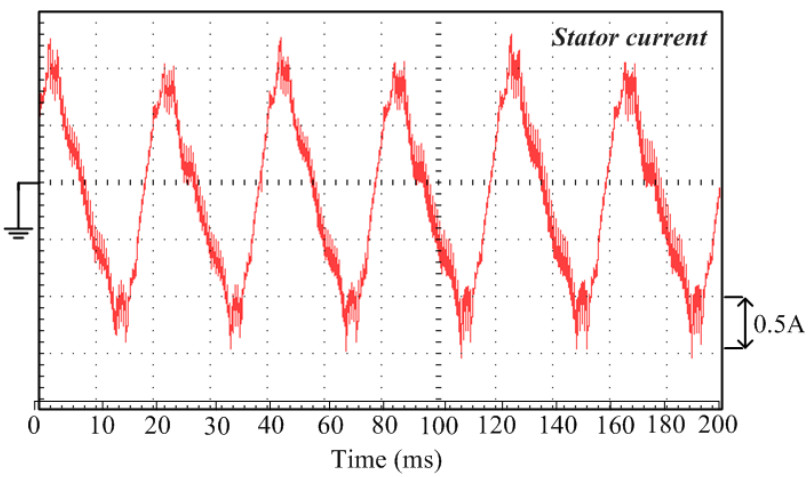

(e)

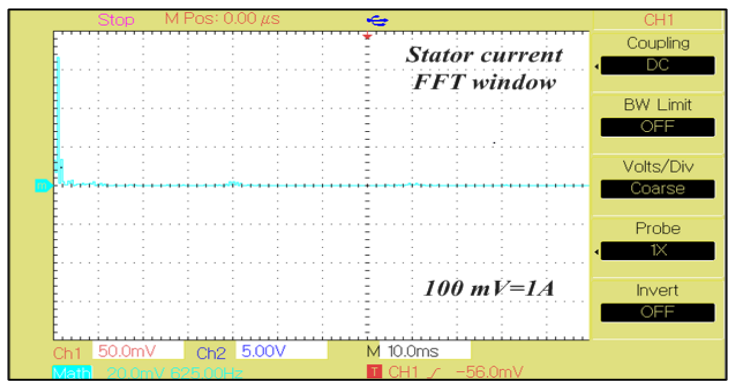


(f)

Fig.11. Experimental setup results

\section{Conclusion}

This paper mainly emphases on the paper is effortless digital implementation of PWM methods to drive the open end induction motor which is supplied using two dc to ac converters (VSI), using various carrierbased Space vector PWM schemes. Various carrier based PWM methods are implemented in MATLAB/Simulink platform so that different switching patterns produced to feed dual inverter fed three phase open end motor. In the present work dSPACE 1104 is used for the digital implementation. Theoretical reflections are certified through the simulation and experimental results. The simulation and hardware results which are obtained from various modulation techniques for the proposed model are secure produced by using voltage and current waveforms, FFT analysis, and the most predominantly the THD is slighter. Theoretical and realistic values are corroborating by simulation and experimentation.

\section{References}

[1] S rao M, Ch. S Babu, S. Satyanarayana ," Design and analysis of variable switching frequency controlled integrated switched mode power converter for class C \& class D appliances", Ain Shams EngJol.,vol.9(2018),p.p2849-2858. doi.org/10.1016/j.asej.2017.10.008.

[2] P.V.S.Sobhan, G.V.N Kumar, Ramana Rao P“" Rotor Levitation and Vibration Control of Hybrid Pole BSRM Using Fuzzy Sliding Mode Controller," International Journal of Innovative Computing, Information and Control, Vol. 14, No. 2, pp.671681,2018

[3] Vijay Babu A R, Manoj Kumar.P, G.S Rao, Design and Modelling of Fuel cell powered Quadratic Boost Converter based Multilevel Inverter, Proceeding of the IEEE International Conference on Innovations in Power and Advanced Computing Technologies (iPACT-2017), VIT University, pp.1-6, April, 2017. Date Added to IEEE Xplore: 04 January 2018, DOI: 10.1109/IPACT.2017.8244962

[4] Narayanan G, D. Zhao, murthy K, Ayyanar and V. Ranganathan, "Space Vector Based Hybrid PWM Techniques for Reduced Current Ripple," in IEEE Transactions on Industrial Electronics, vol. 55, no. 4, pp. 1614-1627, April 2008, doi: 10.1109/TIE.2007.907670.

[5] A. S babu and G. Srinivasa Rao, "Performance Evaluation of SVPWM Methods Using Effective Time Concept for Open-End Winding Induction Motor," 2020 IEEE International Symposium on

Copyright $($ C Authors
Sustainable Energy, Signal Processing and Cyber Security (iSSSC), Gunupur Odisha, India, 2020, pp. 1-6, doi: 10.1109/iSSSC50941.2020.9358853. 